\title{
EDITORIAL
}

\section{HUMANO ¿DEMASIADO HUMANO?}

La pasión por las cosas. Quien pone su pasión en las cosas (...) quita mucho ardor a la pasión por las personas (...).

F. Nietzsche

\section{Cristina Pérez Andrés}

Subdirección General de Epidemiología, Promoción y Educación para la Salud. Dirección General de Salud Pública. Ministerio de Sanidad y Consumo.

Trabajar en la edición de la Revista española de salud pública es útil, entre otras cosas, para comprobar que repetidamente la redacción de la mayoría de los trabajos dirigidos a ella adolece de graves defectos, no sólo gramaticales sino también de contenido y sentido, al confundir a las personas que han participado en una investigación formando parte de la población estudiada, con los datos estadísticos o las categorías de las variables en las que se encuentran resumidas sus características. Dicha redacción, por parte de los autores y autoras de los trabajos, deja mucho que desear en lo que se refiere al respeto a esas personas.

Además de nombrar a estos ciudadanos con adjetivos que les despersonaliza (pacientes, enfermos,...), hecho corriente en otras administraciones públicas en las que se les llama contribuyentes, "veintichobarra», justiciables... convirtiéndoles en objetos de la actividad de la administración, en lugar de permitirles permanecer como sujetos de la acción de la misma, quienes escriben los artículos suelen utilizar expresiones y redacciones que rayan en la más tremenda deshumanización de su trabajo, con el consiguiente peligro de olvidar el fin del mismo.
Expresiones como «nuestras embarazadas», en la que sobra la palabra «nuestras» y falta el vocablo «mujeres», similar a la que suscriben otros autores: «nuestros pacientes», «nuestros asegurados»; las que se refieren a los niños que han participado en un estudio como «los efectivos estudiados»; las que hablan de «la evolución de los primeros casos intervenidos», o las que afirman que «de cada paciente se extrajeron datos», demuestran que han fallado los planes de humanización de la asistencia sanitaria, quizás porque los que se deberían haber puesto en marcha a tiempo son los que tenían que impedir su deshumanización, y no al revés. Pero no sólo no han sido eficaces éstos, sino tampoco otros aspectos de la asistencia que parecen haberse convertido en meros títulos de programas políticos. Por ejemplo, el de la participación activa de los ciudadanos en su atención sanitaria debería haber conllevado la desaparición del abuso de la palabra «paciente» (pasivo) ya que, si dicha participación hubiera funcionado, debería haber sido sustituida por el adjetivo «agente» (activo) y, en cualquier caso, la primera no debería haber implicado nunca la desaparición del sustantivo «persona». 
Quizás haya quien encuentre la justificación de este hecho en la lectura repetida de estas expresiones en la literatura médica pero creo que es más acertado pensar que es la utilización de las mismas en la actividad diaria de los profesionales sanitarios al tratar a las personas a las que atienden la que, más tarde, se traslada a la literatura científica, sin que ello haya sido vivido, hasta ahora, como un síntoma de alarma. De hecho, el caso se repite a diario fuera del contexto de las publicaciones cuando se puede escuchar a profesionales que aseguran trabajar con «VIH positivos», con «los ilegales», o con tumores de mama,...

Olvidar que tras los resultados de una investigación están las personas que los han proporcionado es no tener en cuenta que los mismos están relacionados, no ya con la subjetividad del investigador sino con la de los sujetos investigados. Este olvido permite interpretaciones exageradas del hecho estadístico, que nunca podrá ser igual para contar cosas que para contar acciones, lo que se traduce, al redactar los trabajos para su publicación, en la ausencia de sustantivos que, al ser sustituidos totalmente por los adjetivos que los califican, conlleva la cosificación y desaparición de los sujetos. La epidemiología, diferente de la estadística, y los epidemiólogos deberían poner su interés en que ello no ocurra, no sólo en sus investigaciones sino también en sus programas de actuación y en la escritura de sus textos, para conseguir una relación de mayor respeto de las administraciones hacia los ciudadanos $\mathrm{y}$ ciudadanas para los que existen.

Las revistas que trabajan en la publicación de este tipo de artículos, por nuestra parte, deberíamos esmerarnos en la corrección de estilo de los trabajos aceptados para su publicación, con el fin de evitar que desde las mismas se contribuya a la perpetuación de este tipo de actitudes y, al contrario, ser adalides y pioneras del respeto continuo a las personas, sanas o enfermas, participantes en una investigación o no, colaborando a que no se olvide que también en el sector sanitario se trabaja con un aspecto de la vida que sigue perteneciendo a las personas, las cuales nunca deben ser tratadas como meros objetos de actividad ni como propiedad de la administración. 